\title{
Employee Engagement in CSR: Paving Way to Individual Social Responsibility-A Case Study of Persistent Systems Ltd
}

\author{
${ }^{1}$ Akshita Vyas, ${ }^{2}$ Dr. Anil Sarda \\ ${ }^{1} \mathrm{Ph}$.D. scholar, RTM Nagpur University \\ ${ }^{2}$ Associate Professor, G.S. College of Commerce \& Economics, RTM Nagpur University. \\ Email:akshitavyas5@gmail.com,prof.sarda@gmail.com
}

Received: $20^{\text {th }}$ September 2018, Accepted: $11^{\text {th }}$ October 2018, Published: $31^{\text {st }}$ October 2018

\begin{abstract}
Employee engagement has been one of the most successful tools by HR to maintain work life balance, job satisfaction, and job retention. While a lot of initiatives have been taken with respect to employee's area of interest, a new way has been introduced in the field of CSR wherein it's not just limited to employee's engagement, but employees are indeed the agents of change. The study focuses on employee engagement activities in CSR conducted at Persistent Systems Ltd, using extensive primary data to determine how social volunteering is changing the lives in community and engaging employees on a deeper level.
\end{abstract}

\section{Keywords}

CSR, Employee Engagement, $H R$

\section{Introduction}

\section{Corporate Social Responsibility}

The companies Act 2013 and addition of section 135 in it is a historic step that makes India the $1^{\text {st }}$ country to have a mandatory CSR policy. While there were mixed reactions from the industry, steadily CSR is now an integral part of a Corporate's life. In recent times, CSR has also become a very good driver of employee engagement at some companies and has marked its presence.

\section{Employee Engagement:}

This has been HR's most favourable tool to achieve employee satisfaction, employee retention and improving work life balance. Employee engagement initiatives takes care of an employee's interest, creative quotient, and family's involvement at workplace.

\footnotetext{
About the Company

Persistent Systems Ltd a 28 yrs young IT company, established in the year 1990. PSL started addressing social issues from the year 1995 and established its own Foundation in the year 2009, which states it is a company that does CSR not because they have to do it, but who always loved doing it.

PSL's focus areas are Education, Health \& community development but one of the integral part is employee engagement wherein employees contribute through donation, time \& efforts.

This paper will focus on how CSR and social volunteering has proved to be an important aspect in employee engagement in terms of their involvement, commitment and sensitisation.
}

\section{Methodology}

The research paper is extensively based on primary data which includes questionnaire from the employees and interviews. The secondary data will include the actual and factual statistics of employee volunteering at Persistent Systems Ltd.

\section{Need for Study}

While the importance of CSR and the ideology of business giving back to society is globally accepted, a lot of companies still resist and take CSR as another obligation imposed on them as a tax. The companies which have been doing CSR genuinely have felt the need of involving employees in CSR, right from leadership till the new joiners. The giving back 'together' phenomenon is now taking a toll in the corporates, but good practices needs to be shared by all in order to make it effective. The paper talks about various initiatives taken by Persistent Systems Ltd in CSR as a medium of employee engagement which is known as social volunteering in the organisation.

\section{Objectives}
1. To study various CSR volunteering activities taken by Persistent Systems Ltd
2. To study the involvement of employees in CSR activities 


\section{Hypothesis}

H0: Employees at Persistent Systems Ltd are not engaged in CSR activities

H1: Employees at Persistent Systems Ltd are engaged in CSR activities

\section{Research Methodology}

Sources of data:

Primary data has been collected with the help of a structured questionnaire from employees working in various location of Persistent Systems Ltd.

Secondary data has been collected from data available in annual reports, CSR portal by Government and CSR websites and other related platforms.

Sample: Sample size is taken as 100 from employees in all locations of Persistent Systems in India.

\section{Data Analysis}

\section{Primary Data}

Responses from the employees-

1. Are you aware of your organization's CSR Practices?

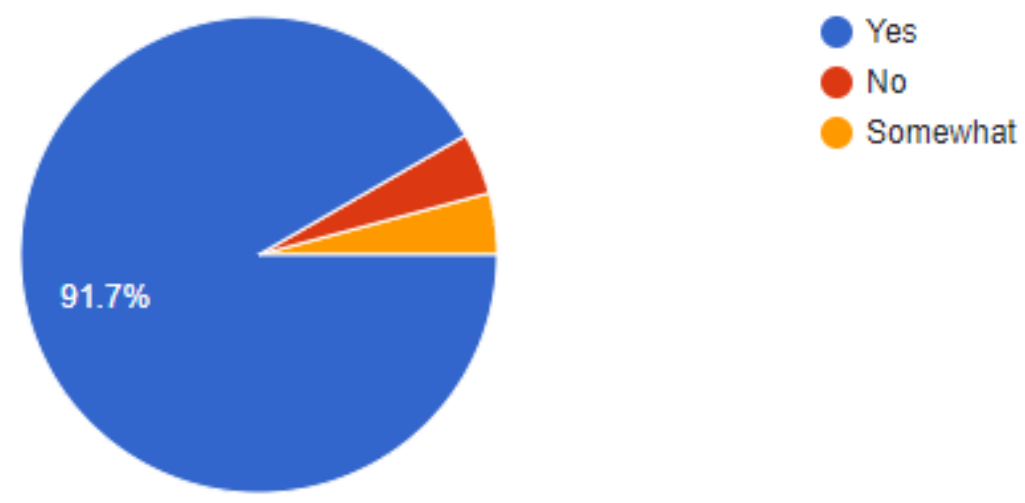

2. Do you agree a corporate should give back to society?

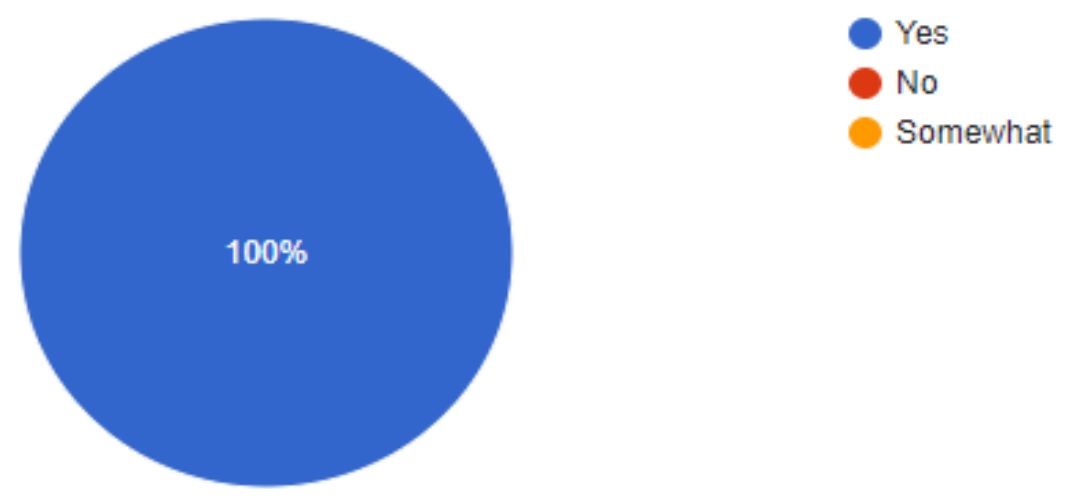

3. Does your company provide opportunities to get engaged in CSR? 


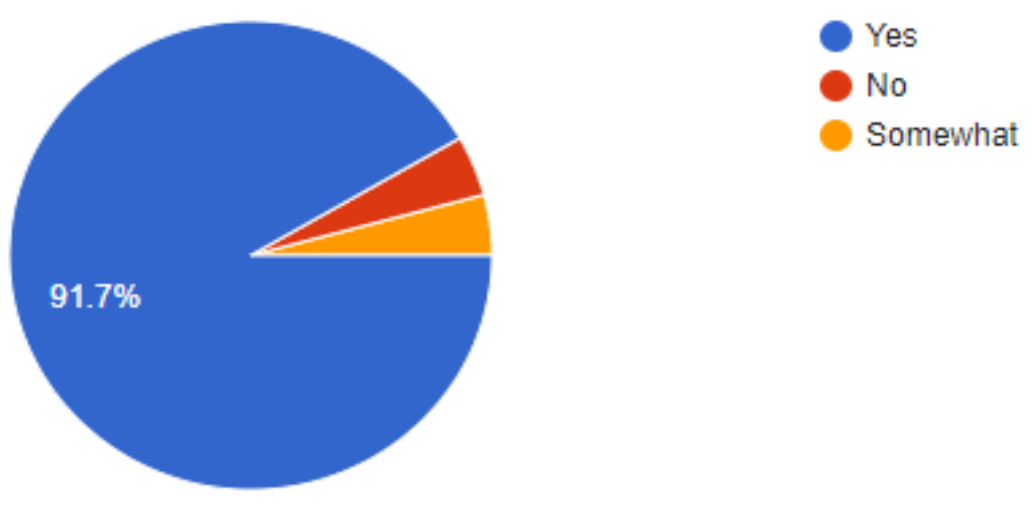

4. In how many CSR activities you have participated?

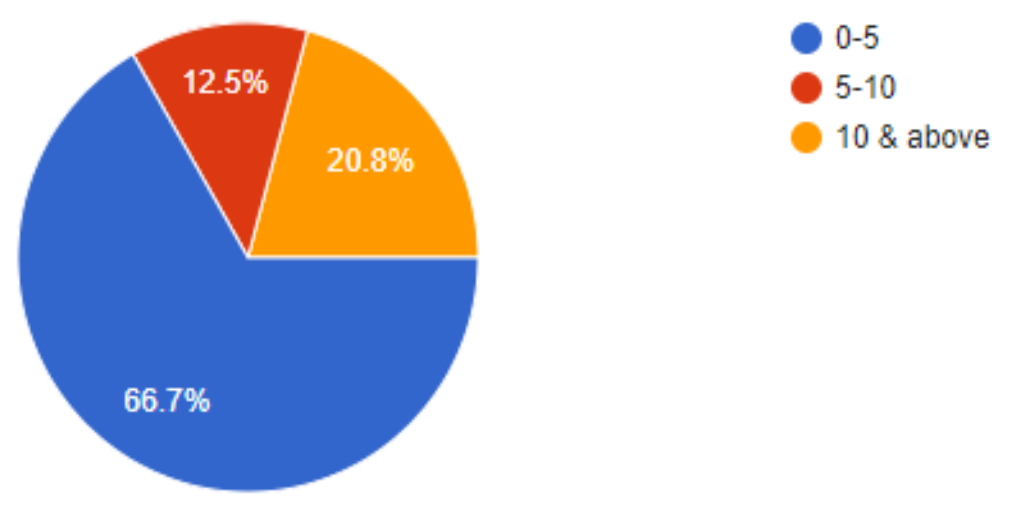

5. Do you agree CSR activities are a good way of employee engagement?

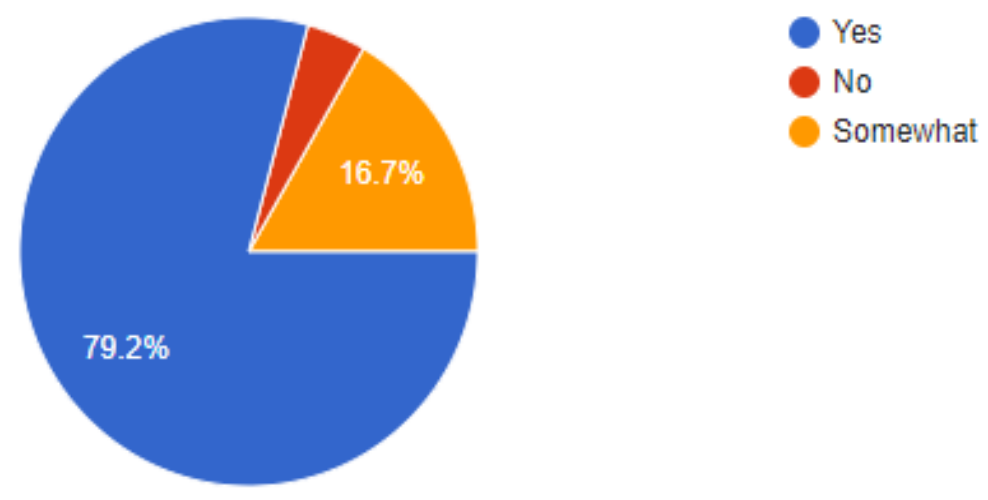

6. How often does your organisation plans a volunteering drive? 


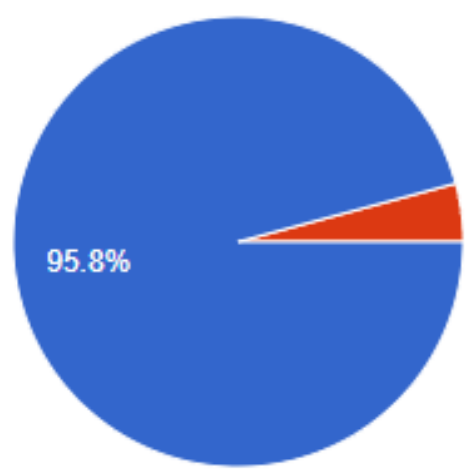

Never

7. Do you receive any reward or appreciation for participating in CSR activities?

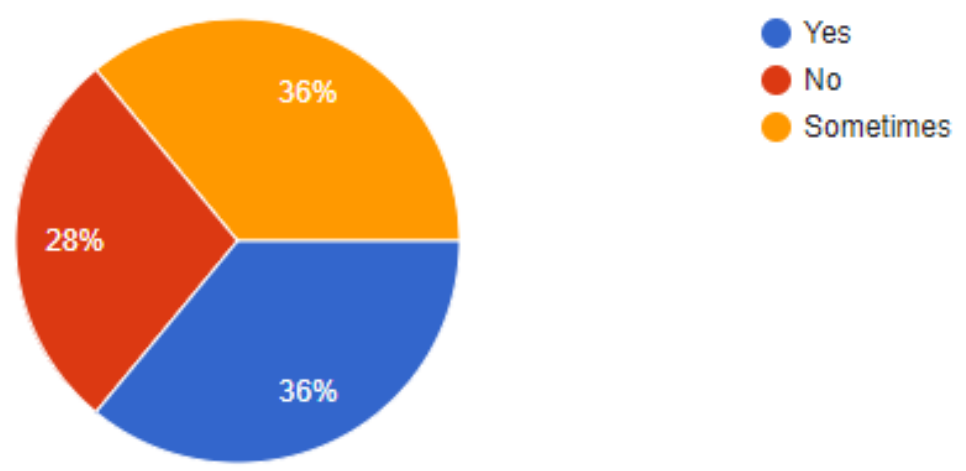

8. Has CSR improved your work place environment?

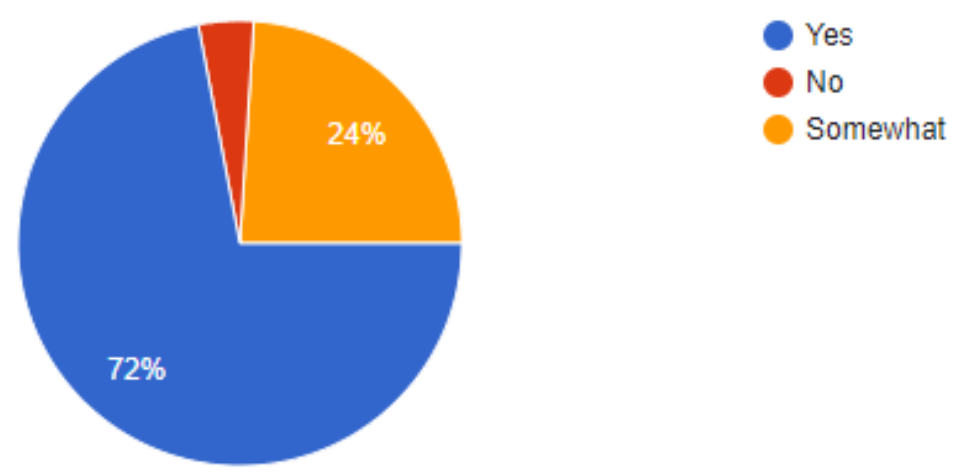

9. Does your family \& friends participate in CSR activities too?

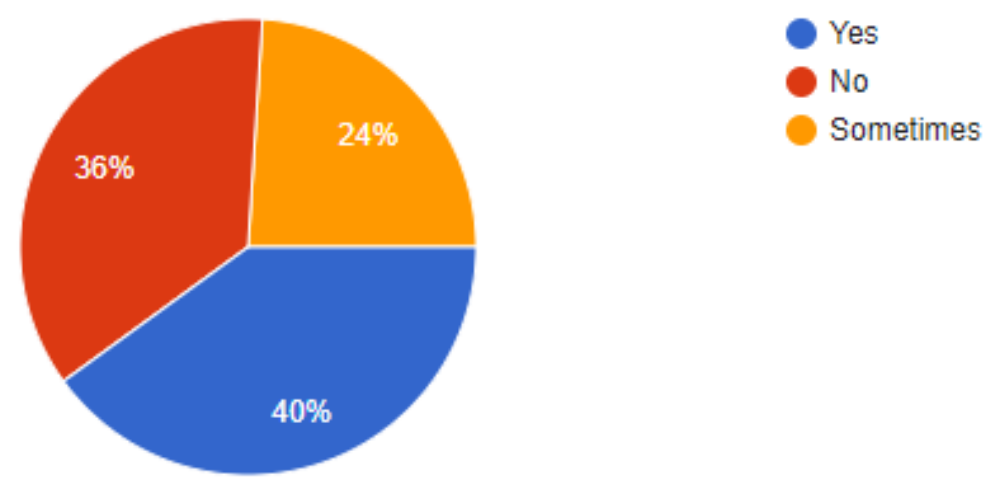


On the rate of 1 to 10 , how would you like to rate your company's CSR?

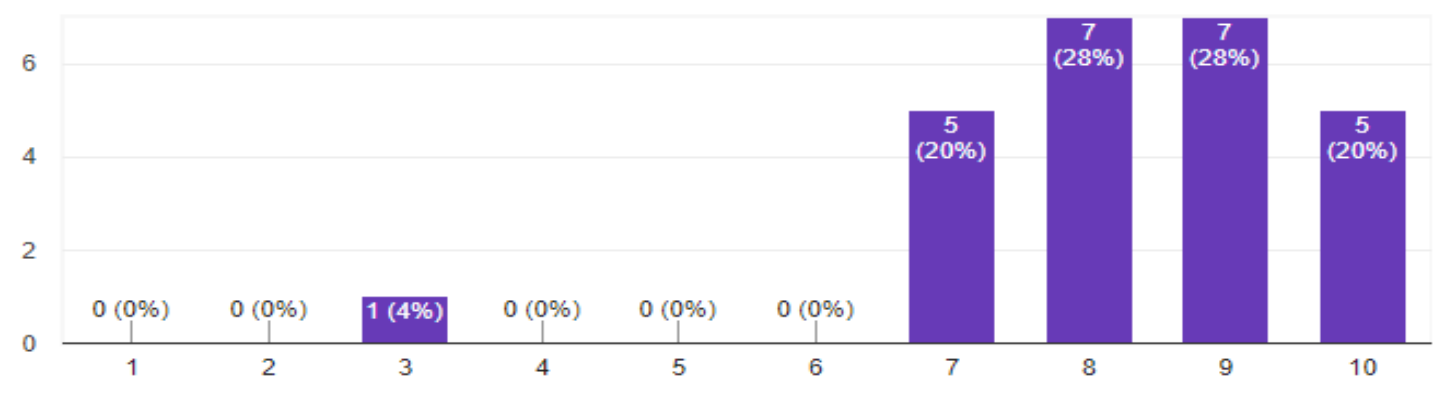

\section{Secondary Data}

Analyzing the secondary data, it is seen that employee volunteering is very high in CSR at all locations. Almost $30 \%$ employees are engaged at every location based on the total no. of employees. On an average 3 volunteering drives are conducted in all the locations by Persistent Foundation team.

\section{Conclusion}

By the people, of the people, for the people. In CSR this democratic line can be termed as the profit which is earned by the people, which belongs to the people in organization i.e of the people, for the people outside office i.e. the community. A very clear mention in the sec 135 law is CSR cannot be done for employees, their welfare or their family. CSR will be for people outside office. Social responsibility was earlier the work of NGOs and Govt only, then after corporate's involvement bigger changes are made, now the time should be of Individual Social Responsibility wherein employees are also contributing through volunteering drives in implementing CSR. This has proven to be a good practice of employee engagement activities in private sectors, and corporates became a very good source to sensitize employees on 'giving back to society'. Based on primary \& secondary data, it can be said that employees are very much engaged in CSR activities at Persistent Systems Ltd. The CSR team organizes activities as per the need in focus areas and in alignment with Sustainable Development Goals.

\section{Pictures of some prominent \& innovative volunteering drives of Persistent Systems Ltd}

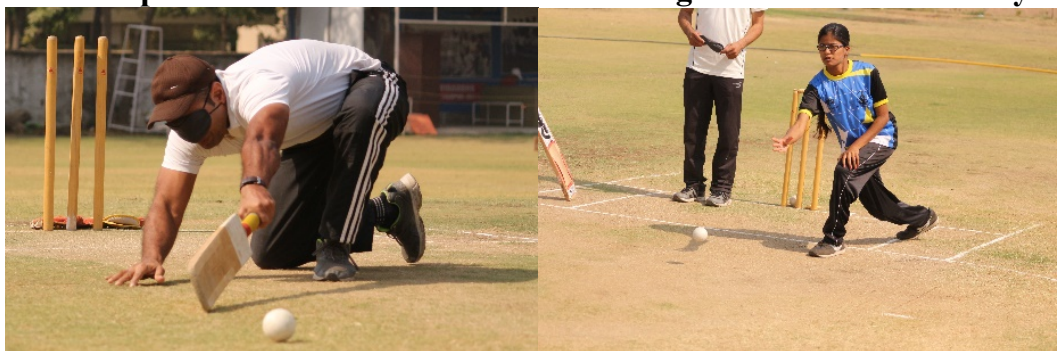

Blind Folded Cricket Match with a Cricket Team of Visually Challenged Girls \& Boys

More news here: https://reacho.in/nagpur/local/persistent-systems-organises-a-friendly-match

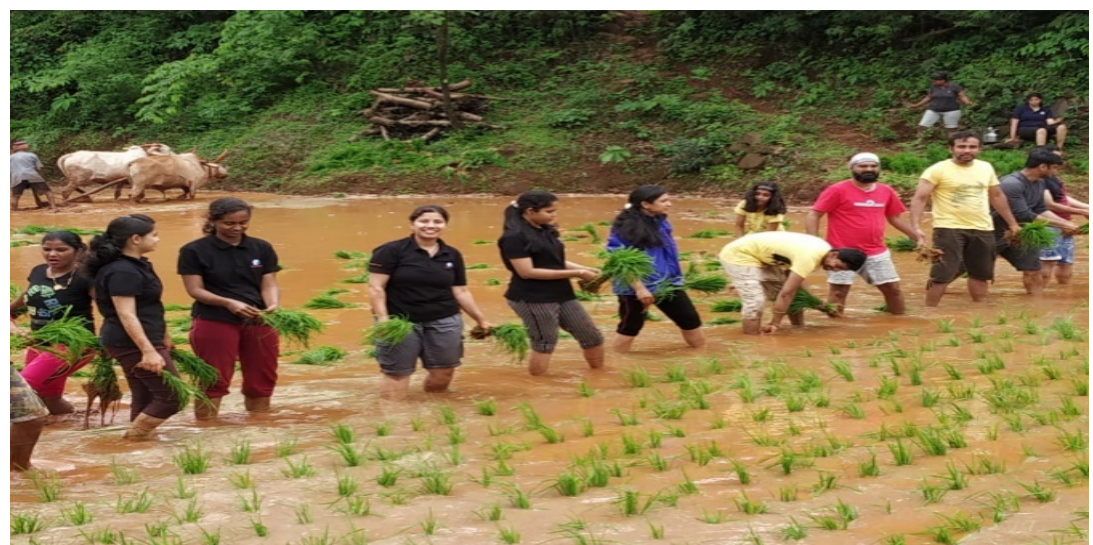

Rice Plantation Activity: A Help to Farmers to Save Labour \& Wages

Like these two there are many more unconventional ways employees at Persistent have been engaged in CSR. 


\section{References}

[1]Mirvis P. Employee Engagement and CSR. CalifManag Rev 2012; 54(4):93-117

[2] Towers Perrin, Towers Perrin Global Workforce Study. 2007-08.

[3]Azada CJ, Rochte M. Workforce for Good Employee Engagement in CSR/Sustainability. 2013.

[4]Strandberg Consulting. The Role of Human Resource Management in Corporate Social Responsibility. Ottawa: Industry Canada. 2009.

[5] Sirota Survey Intelligence. Corporate Social Responsibility contributes to bottom line, improves worker engagement and customer loyalty. 2007.

[6] Fox A. Corporate social responsibility pays off. HR Magazine. 2007 Aug.

[7]Alaganandan BP, Oza A. Employee engagement in times of uncertainty. 2009.

[8] Kenexa Research Institute. Corporate Social Responsibility efforts are recognised by employees. 2007.

[9]Brighter Planet. Employee engagement survey. 2010 Feb.

[10]Skritsovali $\mathrm{K}$. What is the relationship between CSR and employee engagement? RIBM Doctoral Symposium. 2013; 1-12. 